\title{
Dermatology
}

Dermatology 2008;216:361-362

DOI: $\underline{10.1159 / 000117707}$

\section{Systemic Phototoxicity following Intralesional Rose Bengal for Subcutaneous Melanoma Metastases}

\author{
M. Wiener ${ }^{\text {a }}$ D.L. Damian ${ }^{\text {b }}$, J.F. Thompson ${ }^{\text {a }}$ \\ a Sydney Melanoma Unit and ${ }^{\mathrm{b}}$ Department of Dermatology, \\ Sydney Cancer Centre, University of Sydney at Royal Prince \\ Alfred Hospital, Camperdown, Australia
}

\section{Key Words}

Intralesional $\cdot$ Melanoma $\cdot$ Phototoxicity $\cdot$ Rose bengal

Rose bengal is a water-soluble xanthine dye. At present, its main medical use is as a topical agent in ophthalmology. However, there is growing interest in its potential for the treatment of cancer, with promising evidence for efficacy as a local treatment for melanoma metastases [1]. In vitro studies have demonstrated its ability to induce cell death in melanoma cells whilst sparing normal fibroblasts [1]. The mechanism of action in this setting is yet to be fully determined. Xanthine dyes are known to react with ultraviolet and visible light to produce singlet oxygen, which is a key mediator of phototoxic (photodynamic) reactions [2]. Animal studies using rose bengal have demonstrated local phototoxicity, but there are as yet no reports of local or systemic phototoxic reactions in humans $[3,4]$.

\section{Report of a Case}

A 73-year-old woman with no history of primary melanoma presented with several 0.8 - to $4.4-\mathrm{cm}$ subcutaneous nodules on the right lower leg. A histological diagnosis of melanoma was made on core biopsy, and staging investigations revealed no other evidence of metastatic disease. The patient elected to enter a clinical trial of intralesional chemo-ablation therapy using rose bengal. A total volume of $15 \mathrm{ml} 10 \%$ rose bengal solution (1,500 $\mathrm{mg} ; 13 \mathrm{mg} \mathrm{kg}^{-1}$ ) in $0.9 \%$ saline was injected into 2 nodules. There was no history of photosensitivity, auto-immunity, drug allergy or prior exposure to rose bengal. The patient's medications included an antihypertensive containing irbesartan $300 \mathrm{mg}$ plus hydrochlorothiazide $12.5 \mathrm{mg}$, which she had taken for 8 years with no adverse effects.

Within 30 min of rose bengal injection the patient developed mild, asymptomatic red discolouration of the face and scalp. Her condition remained unchanged following observation in a room illuminated with standard fluorescent lighting for $2.5 \mathrm{~h}$, and she was allowed home. The following morning she returned with marked erythema and oedema of the face (fig. 1) and dorsal hands.

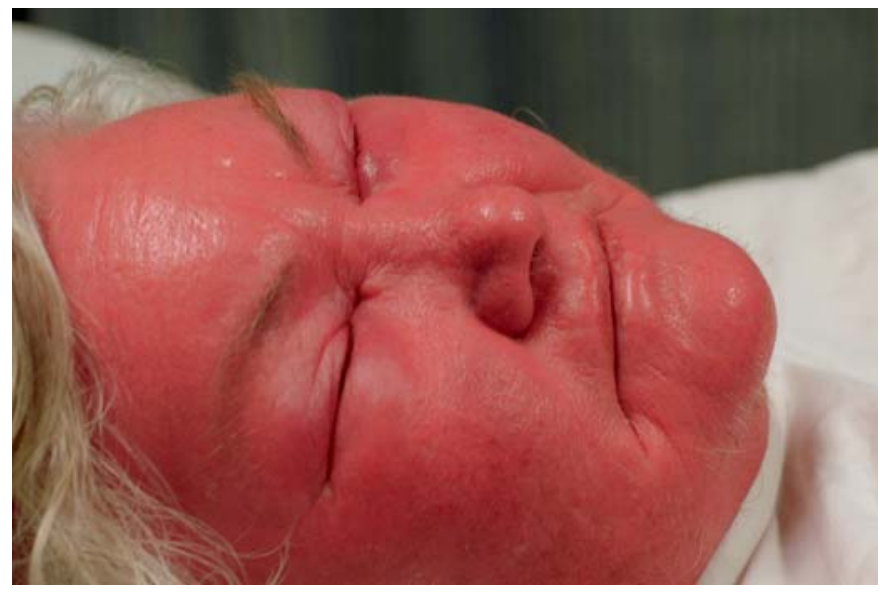

Fig. 1. Appearance on day 1 after treatment, with marked erythema and oedema of the face.

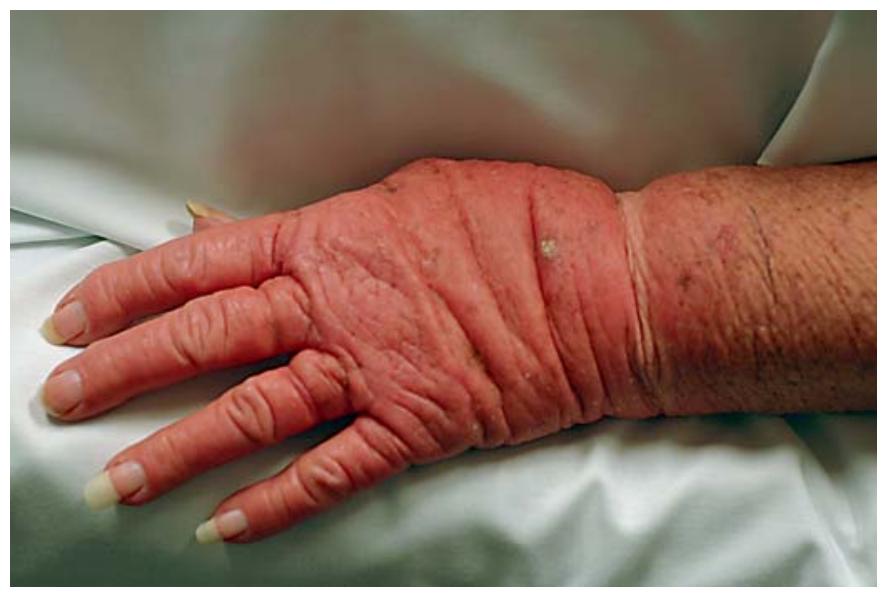

Fig. 2. Absence of erythema beneath the watch strap.

She had been exposed to strong sunlight through a car windscreen for $\sim 2 \mathrm{~h}$ on the previous day and also on return to the hospital. The erythema was limited to areas of light exposure with a band of unaffected skin beneath her watch strap (fig. 2). There was no phototoxicity at the covered injection sites. The patient was systemically well but did report passing red-coloured stools. A diagnosis of photosensitivity was made and she was admitted for treatment with steroids, antihistamines and photoprotection in the high-dependency unit. The oedema and erythema were

\section{KARGER}

() 2008 S. Karger AG, Basel

Fax +41613061234

E-Mail karger@karger.ch

www.karger.com 
maximal on day 2 when a purpuric rash appeared on the dorsa of both hands. The swelling and erythema resolved over 5 days and the purpura of the hands resolved within 6 weeks. All blood samples taken within $8 \mathrm{~h}$ of admission were haemolysed. Subsequent full-blood count, electrolytes and liver function tests, including serum albumin, were unremarkable. Ophthalmic examination was normal.

The injected tumour deposits underwent necrosis and large portions could be lifted off at 14 days after injection.

\section{Comment}

Photosensitivity reactions may be photoallergic or, more commonly, phototoxic [5]. In order for systemic phototoxic effects to occur following intralesional injection, there must be drug entry from the injection site into the intravascular compartment, which would be expected to increase with the volume of drug injected and the vascularity of the tumour. We hypothesise that, in our patient, injection of the metastases formed an extravascular reservoir of dye from which there was systemic uptake over a period of hours or even days, causing prolonged haematogenous distribution of dye. In contrast, an inadvertent intravascular dose would have been rapidly eliminated via the liver, causing only brief susceptibility to phototoxicity [6, 7]. Our patient reported passing red faeces, which supports the hypothesis that systemic uptake was occurring from this extravascular compartment with subsequent excretion via the biliary system.

In rabbits, local phototoxicity can occur following direct application of rose bengal to abraded skin with as little as $5 \mathrm{~min}$ direct summer sunlight, or following intradermal injection, and takes place over a UVA-visible light action spectrum (320-700 $\mathrm{nm})$, with a peak in the 400 - to $600-\mathrm{nm}$ range $[3,4]$. Our patient was exposed to $\sim 120 \mathrm{~min}$ of bright sunlight filtered through glass on the day of injection and again the next day, but at areas distant from the injection site. The haemolysed blood samples in this case had not been protected from light, a measure that has previously been required to prevent haemolysis following systemic administration of rose bengal in humans $[6,7]$.

Thiazide diuretics are known photosensitisers and it is possible that the combination of thiazide and rose bengal produced a synergistic phototoxic effect [8]. Indeed, the reactions resulting from thiazide photosensitivity can be purpuric, as was the case in our patient [9]. Previous patients in this melanoma chemo-abla- tion trial have received doses up to $7.4 \mathrm{mg} \mathrm{kg}^{-1}$ without phototoxicity, although it has been standard advice to avoid deliberate sun exposure in the post-treatment period.

Our finding that systemic phototoxicity can occur following intralesional injections of rose bengal leads us to recommend strict photoprotection for all patients in trials of intralesional chemo-ablation therapy using this agent.

\section{Statement on Financial Disclosure/Conflict of Interest}

The reported data were obtained through a clinical trial of intralesional rose bengal that was sponsored by Provectus Pharmaceuticals, Inc. Professor Thompson is a Principal Investigator for this trial.

\section{References}

1 Mousavi H, Zhang X, Gillespie S, et al: Rose Bengal induces dual modes of cell death in melanoma cells and has clinical activity against melanoma. Melanoma Res 2006;16(suppl 1):S8.

2 Ochsner M: Photophysical and photobiological processes in the photodynamic therapy of tumours. J Photochem Photobiol B 1997;39:1-18.

3 Morikawa F, Fukuda M, Naganuma M, Nakayama Y: Phototoxic reaction to xanthene dyes induced by visible light. J Dermatol 1976;3:5967.

4 Ranadive NS, Menon IA, Shirwadkar S, Persad SD: Quantitation of cutaneous inflammation induced by reactive species generated by UVvisible irradiation of rose bengal. Inflammation 1989;13:483-494.

5 Epstein JH: Phototoxicity and photoallergy. Semin Cutan Med Surg 1999;18:274-284.

6 6 Delprat GD, Epstein MD, Kerr WJ: A new liver function test: the elimination of Rose Bengal when injected into the circulation of human subjects. Arch Intern Med 1924;34:533-541.

7 Kerr WJ, Delprat GD, Epstein NN, Dunievitz MD: The Rose Bengal test for liver function: studies on the rate of elimination from the circulation in man. JAMA 1925;85:942-946.

8 Harber LC, Lashinsky AM, Baer RL: Photosensitivity due to chlorothiazide and hydrochlorothiazide. N Engl J Med 1959;261:1378-1381.

-9 Jaffe MO, Kierland RR: Purpura due to chlorothiazide (diuril). JAMA $1958 ; 168: 2264-2265$

Prof. J.F. Thompson, MD

Sydney Melanoma Unit, Royal Prince Alfred Hospital Missenden Road, Camperdown, NSW 2050 (Australia) Tel. +6129515 5072, Fax +6129550613688

E-Mail john.thompson@smu.org.au 